\title{
MIGRACIÓN Y CAMBIO SOCIOCULTURAL EN DOS COMUNIDADES RURALES DEL DEPARTAMENTO DE CHALATENANGO, EL SALVADOR
}

\author{
Patricia Castro Fuentes ${ }^{1}$ \\ Universidad de El Salvador \\ patycastrofuentes@gmail.com
}

\section{RESUMEN}

Este artículo presenta resultados de la investigación «Género y migración: Recomposición Familiar», que fue llevada a cabo en los municipios de Comalapa y Concepción Quezaltepeque del Departamento de Chalatenango, en El Salvador; cuyo trabajo de campo se realizó entre 2009 y 2010. De esa investigación se ha retomado el análisis del fenómeno migratorio que experimenta El Salvador desde la perspectiva de la hibridación cultural, y se centra en la vida cotidiana de los municipios antes mencionados con la intención de comparar las dinámicas culturales que se establecen en ambos, tomando en cuenta que en el primero las personas migran hacia EUA y en el segundo mayoritariamente a Italia.

Palabras clave: migración, hibridación cultural, familia. 


\title{
MIGRATION AND SOCIOCULTURAL CHANGE IN TWO RURAL COMMUNITIES FROM CHALATENANGO, EL SALVADOR
}

\begin{abstract}
This article presents results from the piece of research titled «Gender and Migration: Family Recomposition.» This study was conducted in the municipalities of Comalapa and Concepción Quezaltepeque in Chalatenango, El Salvador. Fieldwork was carried out between 2009 and 2010. The analysis of the migration phenomenon experienced in El Salvador has been taken from this piece of research. This analysis was made from a cultural hybridization perspective and focuses on the everyday life in the aforementioned municipalities. The intention is to compare the cultural dynamics established between the two, taking into consideration that in the former, people migrate to the USA, whereas in the latter they mostly migrate to Italy.
\end{abstract}

Key words: migration, cultural hybridization, family. 


\section{INTRODUCCIÓN}

El fenómeno migratorio internacional tiene que ver no solo con el flujo de las remesas económicas y su impacto en la economía nacional, sino también con los hechos cotidianos que se trasforman con el constante flujo de personas que toman la decisión de irse, junto a las que retornan al lugar de origen. Este artículo presenta resultados de la investigación «Género y migración: Recomposición Familiar», que fue llevada a cabo en los municipios de Comalapa y Concepción Quezaltepeque, en el Departamento de Chalatenango, El Salvador; cuyo trabajo de campo se realizó entre 2009 y 2011. Los hallazgos etnográficos fueron obtenidos a partir de entrevistas semiestructuradas y a profundidad, lo mismo que por medio de observación participante durante la convivencia prolongada en las dos municipalidades en cuestión. De esa investigación se ha retomado el análisis del fenómeno migratorio que experimenta El Salvador desde la perspectiva de la hibridación cultural y se centra en la vida cotidiana de los municipios antes mencionados con la intención de comparar las dinámicas culturales que se establecen en ambos, tomando en cuenta que en el primero las personas migran hacia los Estados Unidos de Norte América (EEUU) y en el segundo mayoritariamente a Italia.

La sociedad salvadoreña está atravesada trasversalmente por el fenómeno migratorio, y sus implicaciones se manifiestan en múltiples cambios, tanto en el área rural como en la ciudad, y van desde factores económicos, como las remesas, hasta aspectos que tienen que ver con la vida cotidiana de las personas. Mi argumento es que el análisis sobre los flujos migratorios recientes en El Salvador permitirá entender cómo estos cambian y se articulan de acuerdo con circunstancias específicas de la sociedad y de las personas mismas, provocando cambios socioculturales diferenciados a partir de las trayectorias migrantes.

En El Salvador, el fenómeno de la migración internacional es de larga data (PNUD 2005: 31) y a través del tiempo estas migraciones han respondido a diferentes motivaciones. Los flujos migratorios más recientes muestran que la mayoría de las personas que emigran lo hace de forma ilegal (FUNDE 2007, PNUD 2005), a pesar de ello, las personas migrantes 
adoptan nuevas pautas culturales en los lugares de destino que también tienen influencia en las trasformaciones en sus localidades de origen.

Para su mejor comprensión, este artículo presenta un contexto nacional, departamental y local; posteriormente explica los flujos migratorios que han afectado tanto a Comalapa como a Concepción Quezaltepeque: El patrón migratorio de los años 20 a los 80 y el patrón migratorio de los años subsiguientes. Finalmente se reflexiona sobre las trasformaciones de normas, valores y símbolos culturales asociados a los procesos migratorios.

\section{PANORAMA DE LA MIGRACIÓN SALVADOREÑA}

Según señala el Informe de Desarrollo Humano 2005 de PNUD, en El Salvador, puede hablarse de cuatro periodos migratorios. El primero abarca desde 1920 hasta 1969, donde la principal causa expulsora fue la falta de tierras y empleo sobre todo en la zona rural, por lo que según el mismo informe, el principal destino fueron las plantaciones bananeras del norte de Honduras. El segundo se enmarca entre los años 1970 y 1979, teniendo como antesala la guerra entre El Salvador y Honduras en 1969, el clima de inestabilidad política, la represión que se gestaba, y la falta de tierra y empleo. En esta etapa, el flujo migratorio comienza a dirigirse hacia EEUU, formándose las primeras redes migratorias, las cuales, debido a las condiciones que les ofrecía ese país, legalizaron su situación y posteriormente ayudaron a migrar de manera legal a sus familiares y/o personas cercanas. El tercer periodo se ubicaba entre 1980 y 1991 correspondiendo al momento más duro del conflicto armado salvadoreño, donde la mayoría de personas emigrantes lo hicieron de forma ilegal y «los mojados» [también «mojadas»] arriesgaron sus vidas para llegar «al norte». El cuarto periodo de este proceso corresponde de 1992 hasta 2005, a partir de la firma de los Acuerdos de Paz. En este periodo todo apuntaba a que este flujo disminuiría, pero sucedió todo lo contrario, aumentó. La desaceleración de la economía, los estragos del huracán Mitch en 1998, los terremotos de 2001, el desempleo, la delincuencia y la búsqueda del «sueño americano», que cada vez más «hermanas y hermanos» lejanos alcanzan, motivaron flujos migratorios sin precedentes, especialmente a EEUU. 
El Ministerio de Relaciones Exteriores de El Salvador ha desarrollado estimaciones de la población que puede considerarse salvadoreña en Estados Unidos y el resto del mundo. Aunque las cifras no son exactas, presumen que un promedio de 3.3 millones de salvadoreños están distribuidos en diferentes lugares. La misma fuente señala además que uno de cada tres salvadoreños se encuentra en el exterior, y de ese total 2.9 millones, es decir 88\% radica en Estados Unidos (PNUD 2005: 38). Es innegable, entonces, que con tal flujo de personas yendo y viniendo, y sin duda alguna incrementando, se propician cambios culturales a través de ese corredor que se establece entre las personas que se quedan y las que se van, y se concretan en los bienes de consumo cultural.

Un estudio realizado sobre personas migrantes en Washington DC por Repak, en el año 1995, destaca que fueron la mujeres las que primero llegaron a EEUU. Señala que en la década de los 60 y 70 de ese mismo siglo, $70 \%$ de migrantes de Centro y Sur América en Washington DC eran mujeres. Ese mismo estudio además resalta que esas mujeres pioneras facilitaron la llegada de la ola migratoria de los años 80 . Y afirma que esas mujeres viajaron de forma autónoma sin la colaboración de la pareja o familiares (Repak 1995, en PNUD 2005: 334). Esta conducta puede explicarse debido a que en El Salvador las mujeres rurales ya acostumbraban salir de sus comunidades de origen para buscar trabajo en zonas urbanas, donde llegaban a trabajar en hogares como empleadas domésticas o a trabajar en fábricas (Repak 1995, Menjívar 2000, en PNUD 2005: 334). El Censo Decenal de Estados Unidos de 1980 (ibídem) reportaba que de la población salvadoreña que residía en ese año, $55.9 \%$ eran mujeres y $44.1 \%$ hombres. Con el inicio del conflicto armado los flujos de migrantes hacia Estados Unidos pasaron a ser dominados por los hombres, que salían del país debido a la difícil situación para evitar así ser reclutados [por el ejército o la guerrilla].

En todo caso, las causas y motivaciones por las cuales las personas migran, lo mismo que los factores por los cuales El Salvador es un país expulsor, son complejas. De ahí la importancia de dar cuenta de los cambios culturales que las migraciones han traído consigo 
y la manera en que están afectando particularmente la vida de las mujeres, tomando en cuenta las nuevas formas en que las familias se están reconfigurando a partir de la decisión sobre la partida de la madre, el padre, hermana o hermano, tía o tío, etc., provocando con ello cambios y reacomodos que permiten la continuidad de la vida diaria en la comunidad de origen. Estos reacomodos son parte de las nuevas reconfiguraciones familiares que trae consigo el fenómeno migratorio, donde la jefatura de los hogares descansa, en muchos casos, en la figura de las abuelas y de las madres. De esta manera, como una consecuencia de la cuestión migratoria, es frecuente encontrar familias en las que la madre, el padre o ambos viven permanentemente en el país de destino, lo que implica reorganizar el hogar a partir de esa salida o igualmente reorganizarlo a partir del retorno al seno familiar de alguno de ellos. Esas recomposiciones que se dan a lo largo de todo el proceso migratorio están modificando los valores, las cosmovisiones y los significados mismos de lo que es una familia en el aquí y en el allá de manera simultánea.

Lo anterior tiene un peso considerable si se toma en cuenta el número de familias salvadoreñas impactadas por el hecho migratorio. Aunque los números al respecto son inciertos (PNUD 2005: 290), la información relacionada indica que se trata de un fenómeno de gran envergadura. Esa misma fuente señala que en 2004 había en El Salvador 362,189 familias, $22.3 \%$ del total del país, que recibían remesas. Pero si se toma en cuenta que no todas las personas migrantes envían remesas — por vínculos familiares diluidos, por desempleo temporal o porque sus familias no lo necesitan y sus vínculos son a través de regalos y visitas-, se puede intuir que el número de familias vinculado a las migraciones es mucho mayor que esa cifra.

\section{CONTEXTO NACIONAL, DEPARTAMENTAL Y LOCAL}

Las siguientes páginas intentan acercarse al contexto sociocultural de los dos municipios estudiados en el Departamento de Chalatenango: Comalapa y Concepción Quezaltepeque; particularmente en cómo se están reconfigurando sus familias a partir del hecho migratorio. 


\section{EL CONTEXTO NACIONAL Y DEPARTAMENTAL}

Las migraciones modifican las relaciones entre las personas e implican un cambio sustancial en las formas básicas de convivencia, que pasan entre otras cosas por el flujo constante de remesas económicas, que debido al importante papel que juegan representan la oportunidad de suplir las carencias en las que por años han vivido quienes se quedan y retribuyen y confortan los afectos de quienes se van. Todos esos cambios que incorporan otras maneras de ver y vivir la vida, insertados en un contexto nacional y local, ofrecen un matiz más amplio para interpretar el hecho migratorio.

Así, se empieza trayendo a cuenta que El Salvador es el país más pequeño, más densamente poblado y, posiblemente, con los más altos índices de degradación ambiental en Centroamérica, con una población de un poco más de 6.2 millones de habitantes (Gammage 2004: 2), aunque según el censo de población y vivienda de 2007, la población total de El Salvador es de 5,774,113 habitantes. Esos resultados del censo reflejan que la población real es menor a la proyectada, debido a que para el año 2007, según la Dirección General de Estadística y Vivienda (DIGESTYC), se tenía una estimación de 7,104,999 personas, diferencia que es atribuida a la disminución de la tasa de fecundidad y a una elevada migración, entre otras razones.

En ese contexto, el departamento de Chalatenango se localiza en la parte Central Norte de la República de El Salvador (Figura 1); territorialmente ocupa el cuarto lugar en extensión con un total de 2,016.6 km², y está dividido en 33 municipios y 191 cantones. Con la regionalización de El Salvador en 1998, propuesta por la Comisión Nacional de Desarrollo (CND), el Departamento de Chalatenango junto a algunos municipios de los Departamentos de Santa Ana, La Libertad, San Salvador, Cuscatlán y Cabañas se ubica en la denominada Región Norte del Río Lempa (PNUD 2007: 16). Según la CND, la zona norte del país es la región históricamente marginada y desarticulada de las oportunidades de desarrollo. Pero destaca que la zona es estratégica para el desarrollo nacional, entre otras razones porque se ubica en el centro de la cuenca del río Lempa; estructuralmente es la región más segura, por 
la menor amenaza de riesgos ambientales y geológicos potencialmente catastróficos sismos, inundaciones, vulcanismo-; en ella, además se genera la energía hidroeléctrica que consume el país y se produce agua potable para la región metropolitana de San Salvador y otras áreas urbanas, además está fuertemente vinculada económica, social y ambientalmente con las poblaciones del sur de Honduras.

Figura 1. Ubicación geográfica de Chalatenango.

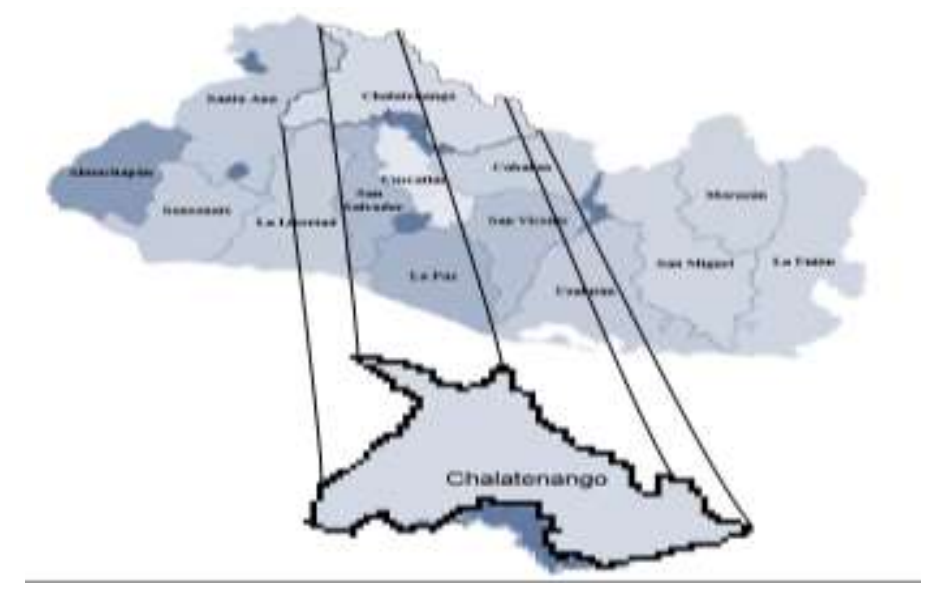

Fuente: PRISMA 2006.

Debido a la importancia señalada, CND formuló ejes que promovieran el propio desarrollo y crecimiento de la región, entre ellos: la construcción de la Carretera Longitudinal del Norte, con un sistema de interconexiones para crear una conectividad dentro de la región y entre esta y otras zonas del país y Centroamérica; la construcción de una Agenda de Desarrollo de la cuenca del Río Lempa; el fomento de la planificación microrregional articulada con los procesos estratégicos de la región, como una forma de gestión local territorial y la revitalización de territorios productivos y el desarrollo de la base empresarial local. En ese rubro los actores locales también generan sus proyectos de desarrollo, y a partir de 1999 se organiza la Mancomunidad La Montañona, a la que pertenecen los municipios de Comalapa y Concepción Quezaltepeque (Figura 2). 
Figura 2. Contexto geográfico de La Montañona.

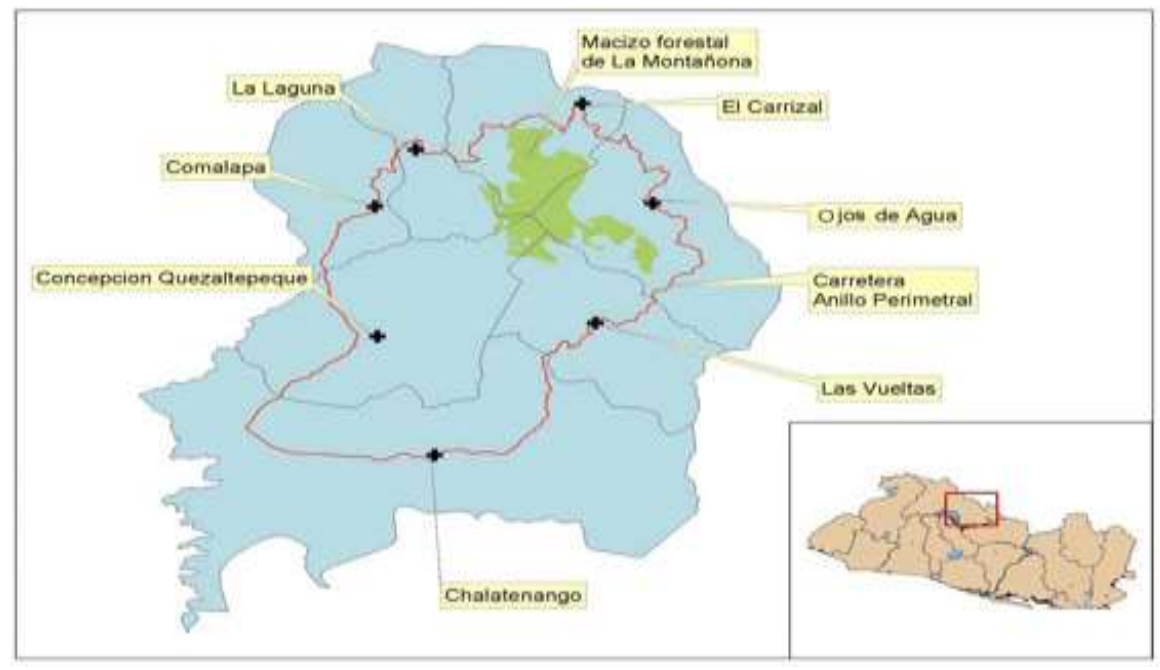

Fuente: PRISMA 2006.

Asimismo, Chalatenango fue cuna de los movimientos populares, convirtiéndose a finales de los años 70 en un importante tejido de organización social fuertemente ligada a la base de la Iglesia católica. Chalatenango se convirtió en uno de los principales escenarios de la guerra civil que vivió El Salvador entre 1980 y 1992. Reconociéndose como uno de los principales protagonistas en la incidencia de los cambios políticos acontecidos a nivel nacional (ACISAM 2008: 8). Por otra parte, a partir de los datos del VI Censo de Población y V de Vivienda 2007, en el departamento se registra una población de 192,788 habitantes, que equivale a $3.4 \%$ de la población total del país. De estos habitantes, $52.2 \%$ son mujeres y $47.8 \%$ son hombres, y es el departamento con menor densidad poblacional de El Salvador, con 96 habitantes por kilómetro cuadrado.

CONTEXTO LOCAL

LA MANCOMUNIDAD LA MONTAÑONA

Entre Concepción Quezaltepeque y Comalapa existen diferencias sustanciales en cuanto a 
extensión territorial, población y servicios, sin embargo los dos forman parte de La Mancomunidad La Montañona, asociación de siete municipalidades: Chalatenango, Concepción Quezaltepeque, Comalapa, La Laguna, El Carrizal, Ojos de Agua y Las Vueltas. Creada formalmente en octubre de 1999, se ubica en el noreste del departamento de Chalatenango, compartiendo el macizo montañoso que lleva el mismo nombre. El bosque de La Montañona tiene una extensión total de 1,437 hectáreas, y es una zona de bosque estratégicamente importante para la provisión de agua con potencial para desarrollar turismo de montaña (PRISMA 2006: 2 y 3).

El trabajo conjunto de los siete municipios que integran esta mancomunidad les permite coordinar apoyos que fortalecen el desarrollo de las municipalidades y de sus habitantes. Una de las primeras acciones conjuntas de La Mancomunidad fue la construcción, en el año 2001, de la carretera perimetral que bordea al macizo montañoso, logrando con ello dinamizar las actividades económicas de la región, y aunque son solo dos las localidades seleccionadas para este estudio no pueden desligarse de este contexto regional-local que le da un matiz particular y genera una dinámica política y social que marca un ritmo de vinculación entre los siete municipios. Asimismo, la carretera perimetral que les une favorece el comercio y las comunicaciones entre ella misma y la zona fronteriza con Honduras. La Mancomunidad permite a los siete gobiernos municipales que la componen una constante comunicación y coordinación de acciones que les facilita ser beneficiarios de la apuesta estratégica del gobierno central y de proyectos de desarrollo financiados por la comunidad internacional.

\section{COMALAPA}

Comalapa está situada a $83 \mathrm{~km}$ de la ciudad capital de San Salvador y pertenece al distrito de Dulce Nombre de María en el Departamento de Chalatenango. Su extensión geográfica es de $28.22 \mathrm{~km}^{2}$, de estos corresponden al área rural $27.72 \mathrm{~km}^{2}$ y al área urbana $0.5 \mathrm{~km}^{2}$. Según datos propios de la Alcaldía, se estiman 4,516 habitantes, de los cuales: 938 (22.13\%) pertenecen a la zona urbana y 3,309 (78.09\%) se ubican en la rural. Para su 
administración, el municipio está conformado por cuatro cantones, dieciséis caseríos, y el casco urbano está dividido en dos barrios: Las Flores y Las Delicias (Plan Estratégico Participativo 2004-2008, Alcaldía Municipal de Comalapa: 15 y 16).

\section{CONCEPCIÓN QUEZALTEPEQUE}

Esta ciudad se encuentra a $77 \mathrm{~km}$ de San Salvador, limita al norte con Comalapa y La Laguna, al noreste y este por Las Vueltas, al sureste y suroeste por Chalatenango, al oeste y noroeste con Santa Rita. El 15 de enero de 1543 se le otorgó el título de pueblo y durante la administración del general Maximiliano Hernández Martínez, por decreto legislativo de 6 de julio de 1938, el título de villa; y en mayo de 2002, el de ciudad. El área del municipio es de $52.54 \mathrm{~km}^{2}$. Administrativamente Concepción Quezaltepeque está dividida en seis cantones y diecisiete caseríos. El casco urbano, que concentra la mayoría de la población, se divide en seis barrios: San Antonio, Las Flores, San José, San Jacinto, Concepción y El Centro. Según el VI Censo de Población y el V de Vivienda 2007, Concepción Quezaltepeque tiene una población total de 6,457 personas, pero los datos de la alcaldía municipal arrojan que en 2009 había 8,966 habitantes, de los cuales 4,627 se encontraban en el casco urbano.

\section{FLUJOS MIGRATORIOS DEL DEPARTAMENTO DE CHALATENANGO}

Los municipios de Comalapa y Concepción Quezaltepeque, separados por 6 kilómetros de distancia y asociados a una misma Mancomunidad, parecería que comparten las mismas dinámicas culturales: tranquilidad y bajos índices de delincuencia, beneficiarios de Fomilenio, mayoritariamente profesan el catolicismo, sus gobiernos municipales son de derecha, comparten un mismo entorno rural, son receptores de remesas, etc. Sin embargo, existen peculiaridades que les hacen diametralmente opuestos y que recuerdan que no se puede generalizar sobre los hechos culturales, que cada dinámica responde a una construcción particular producto de circunstancias específicas.

De esta manera, el primer hecho que salta a la reflexión es el destino de la migración actual y las razones que lo motivaron. A continuación se presentan los flujos migratorios que han 
marcado a estas dos localidades en diferentes momentos del siglo pasado y del presente.

FLUJOS MIGRATORIOS DEL DEPARTAMENTO DE CHALATENANGO, DE LOS 30 A LOS AÑOS 70 La dinámica migratoria particular de estos años, tanto de Concepción Quezaltepeque como de Comalapa, y en ese sentido, el hecho de que hombres y mujeres hayan salido en busca de mejores condiciones de vida para sus familias, ha sido parte de sus vidas y convivencias. Esta situación está dada primero por la migración a Honduras y luego por las migraciones internas hacia el occidente del país debido a las cortas estacionarias del café, y también por las salidas hacia la ciudad capital, San Salvador, por parte de algunas mujeres para emplearse principalmente en el servicio doméstico; lo mismo que casos puntuales de hombres que por comercio de jarcia se desplazaban al oriente del país, particularmente al oriental Departamento de San Miguel.

En ese ir y venir ha habido circunstancias peculiares que han provocado separaciones tanto de hombres como de mujeres, pero que para el caso de la migración hacia Honduras ha sido marcada mayoritariamente por la ausencia masculina en el hogar de origen, representada en el marido, el hijo mayor, el hermano, el tío, etc. A partir de ese hecho se explica cómo en la oleada migratoria que señala PNUD (2005: 31) como primer periodo y que abarca desde 1920 hasta 1969, fueron los hombres quienes emigraron. Aproximadamente a $21 \mathrm{~km}$ de Comalapa y a $27 \mathrm{~km}$ de Concepción Quezaltepeque, siguiendo el camino vecinal, se encuentra un punto fronterizo ciego entre El Salvador y Honduras, pero «si se atravesaban los cerros, a unos 17 km, ya estaban al otro lado», señala un informante. Esta circunstancia permitió una movilización sin mayores riesgos personales y sin que la inversión económica les fuera significativa, porque además «con sólo tortillas y queso que lleváramos para aguantar el viaje y con varios días de camino, ya estábamos cortando banano».

Las motivaciones para incursionar en esos flujos migratorios eran porque «si uno se quería casar, había que irse a Honduras para ganar dinero, si era que alguien estaba huyendo de la justicia, se agarraba para Honduras, si es que uno quería salir de deudas o hacerse de su 
casa, o tener [dinero] para comprar tierras había que irse para Honduras». Un informante señala a este respecto que «allá había trabajo, si la cosa era no más de agarrar camino, no costaba nada, sólo que uno dejaba la familia, pero era para "ganar" [dinero] y traer para las cositas, pero mire, como ahí no más..., pues si se le facilitaba a uno irse y venirse».

No hay claridad del año o quién fue la primer persona en emprender ese viaje, pero por las conversaciones se puede inferir que fue sobre los años 30 del siglo pasado y hasta quizá un poco antes. En general, en las conversaciones con hombres y mujeres se hace referencia a ese viaje que marcó una primera separación en muchas de las familias. Un informante comenta: «me fui un año cabal a ganar dinero para hacer la casa y ya no volví a regresar [a Honduras], pero otros se iban, ganaban [dinero], se venían otro tiempito para acá y se volvían a ir». Resulta interesante que en esa oleada migratoria no se fueron mujeres, especialmente porque en las empresas empacadoras hondureñas de banano se empleaba solamente mano de obra femenina. Algunas personas manifiestan que fue porque el viaje implicaba riesgos y porque la separación era muy larga y no había manera de comunicarse fluidamente, además está de por medio el hecho de que en esa época (años 30, 40 y 50) las mujeres estaban más atadas a su rol de cuidadoras de la casa y los hombres al de protectores y proveedores. Una informante comenta que «sólo hombres se iban porque el trabajo allá se realizaba en el campo, en las bananeras o trabajando la tierra», a lo que su padre agrega que «los salvadoreños éramos bien recibidos por trabajadores, algunos hasta se quedaron, hicieron familia y ya con sus tierras hicieron vida». Pero la gran mayoría de los que se fueron regresaron y se incorporaron de nuevo a la vida del pueblo, volvieron a sus familias, a sus cultivos y retomaron su cotidianidad. La guerra entre ambos países en el año 69 les obligó a regresar aunque no quisieran y a no cruzar de nuevo, salvo riesgos, esa frontera; pero también les obligó a romper lazos de amistad y solidaridad consolidados a través de los años residiendo en diferentes ciudades hondureñas. Esta migración a Honduras fue muy significativa en número ya que «así como hoy se van para el Norte, así se iban para Honduras, eran un montón los que se iban», comenta un informante, por lo que las familias aquí se acomodaron a la separación temporal de uno o varios de sus miembros. 
Sabían con certeza que esa separación les significaba una mejora económica y les implicó organizarse para seguir adelante con sus vidas cotidianas.

Es interesante que, a pesar de la cantidad de años que los hombres se fueron a trabajar a Honduras y a las relaciones que establecieron, las personas en general, tanto en Concepción Quezaltepeque como en Comalapa, se refieren a los hombres y mujeres de Honduras como «la mancha brava», haciendo referencia a la inminente invasión a El Salvador cuando se desató la guerra en 1969 entre ambos países. Durante los años que duró esa migración a Honduras, el cambio más significativo fue que las familias modificaron su estructura y se organizaran para seguir con su cotidianidad, hecho que implicó que las mujeres asumieran la autoridad del hogar mientras los hombres se encontraron fuera, sin embargo no hubo otras trasformaciones culturales significativas en las dinámicas económicas, políticas e inclusive a nivel de infraestructura en estos dos pueblos. Las personas informantes solamente dan cuenta del tipo de trabajo realizado y de las ganancias económicas que les significaban. Si bien, la razón principal que motivó el viaje fue la de obtener dinero para sus familias o proyectos personales - contraer matrimonio, principalmente-, las personas informantes no hablan de acumulación económica, pero sí expresan que «muchos hicieron su casa con lo que ganaron». Construyeron, ampliaron y mejoraron casas, pero siguiendo el modelo tradicional básico y modesto preexistente en el pueblo.

Una posible explicación de este hecho está basada en que la migración se efectuó de una región rural a otra con similares condiciones. La diferencia radicaba casi exclusivamente en la oportunidad de ganar dinero al emplearse en las bananeras y que tan sólo requerían de las habilidades que ya poseían —usar el machete y estar acostumbrado al trabajo que el campo implica: sol, lluvia, jornadas largas, etc.- Asimismo, los medios de comunicación y trasporte en esos años colaboraron con la limitada trasformación de las dinámicas de las comunidades de origen. En un aproximado de 40 años que duró esta oleada migratoria, las condiciones de vida rural se mantuvieron. Al hablar con algunas mujeres, cuyos esposos o padres se fueron de manera temporal — por un año la mayoría-, no tienen conciencia de 
que estaban fuera de su propio contexto cultural, en principio, porque al estar en los campo bananeros se encontraban de alguna manera aislados de las ciudades, y cuando regresaban no traían consigo elementos culturales sustanciales que modificaran su actual entorno familiar y comunitario.

Un segundo momento en el contexto migratorio de Comalapa y Concepción Quezaltepeque corresponde a la migración interna por las cortas estacionarias de café. Estas salidas hacia otras regiones del país, al occidente para el caso, muestran cómo esa movilidad del campo a la ciudad les representa «un nuevo ejercicio de separación temporal» en busca de bienestar personal y familiar. De la misma manera que sucedió con la migración hacia Honduras, las familias se separaron de manera temporal y se reconfiguraron y reestructuraron para seguir con sus vidas en el día a día. En el caso de las cortas de café, el momento de separación fue anualmente y se concretaba entre los meses de octubre a diciembre, prolongándose muchas veces hasta febrero del año siguiente. Esta periodicidad era variable debido a que dependía de los ciclos en que las fincas de café empezaran y terminaran con las tareas de recolección. Además, era común que cuando una finca terminaba su «corta», las personas se trasladaran a otra que todavía tenía algún trabajo que realizar. Lo interesante de esta cosecha estacionaria es que en muchos casos la familia completa se trasladaba a las fincas; o según fueran sus intereses. Podían viajar el padre y los hijos mayores y la madre se quedaba a cargo de la casa y de las hijas e hijos pequeños; o la madre era la que viajaba. Hay casos en los que la hija mayor se quedaba en casa como responsable. Pero en realidad esta decisión de «irse para los cortes» era tomada según las conveniencias del grupo familiar y al objetivo que se perseguía en cuanto a la ganancia económica que se obtuviera con el viaje. En general «el dinero de los cortes» se destinaba para la milpa, subsistencia del hogar, «los estrenos» de la navidad, los útiles escolares, el año nuevo, la «Fiesta» del pueblo y otros gastos relativos a mejoras del hogar, pero esto último en menor grado y dependía de otras prioridades que las familias tuvieran en ese momento.

Aunque las implicaciones de esta separación fueron diferentes para mujeres y hombres, en 
cuanto a las condiciones del desapego familiar, lo cierto es que lo vivieron como momentos duros. Las personas solían irse a «los cortes» en grupos, no solo de familias sino con las personas conocidas, las o los jóvenes que viajaban solos iban recomendados con alguien mayor o familiar. Organizaban los viajes alquilando buses o camiones que les llevaban a la finca directamente. La ventaja de «los cortes», según comentan algunas personas, es que podían retornar con alguna facilidad aprovechando la cercanía con el occidente del país. «Cada quince veníamos a dejar dinero y a ver a los cipotes o hasta nos quedábamos y ya no nos íbamos, todo dependía de la necesidad que tuviéramos. Pero varios se quedaban en "los cortes" hasta dos meses de un sólo», menciona una informante.

Lo mismo que sucedió con la oleada migratoria hacia Honduras, en esta salida a las cortas de café tampoco hubo incorporación de nuevas costumbres o se modificaron valores y significados. Y es que esta migración también les llevó a un contexto rural, de alguna manera aislada, en el sentido de que viajaban de su pueblo a la finca de café y viceversa. Las personas no recuerdan que esas salidas estacionarias les implicaran cambios y reacomodos radicales al interior de sus familias o en las formas de consumo. Pero, aunque no lo expresen de manera explícita, se deduce que esta segunda separación, al realizarse durante varios años consecutivos — diez o más, depende de cada caso particular - les implicó una practicidad a la hora de decidir cuántas personas de una misma familia viajaban y a la hora de continuar con las actividades cotidianas para quienes se quedaban. Empezó a asumirse esa migración como un hecho importante y necesario para el bienestar familiar y no como una situación de aflicción. Fue asumiéndose poco a poco como una acción periódica necesaria.

Otro patrón migratorio importante, no tanto por el número, sino porque fue una acción emprendida por las mujeres, es el que se dio también a partir de la década de los años 60 y 70 , cuando muchas mujeres jóvenes y de mediana edad salieron para trabajar como empleadas domésticas en la zona metropolitana de San Salvador. Se fueron solas, por sus propios medios, y se empleaban en casas de familias. No hay datos exactos de cuántas 
mujeres salieron para emplease, tampoco hay datos concretos sobre en qué periodos salieron más o en cuáles salieron menos, pero sí está claro que sus ingresos permitían sacar adelante a sus familias. Tampoco se puede saber si fue en Comalapa o en Concepción Quezaltepeque de donde salieron más mujeres hacia las áreas urbanas a emplearse. Sin embargo, al hablar sobre este tema, tanto los hombres como las mujeres con quienes se conversó manifiestan que o sus hermanas, hijas, madres e incluso esposas tomaron la decisión, a veces consultada y/o negociada con sus parientes, especialmente en los casos en que dejaban niñas o niños pequeños al cuidado de otra persona de la familia.

En este patrón migratorio surgen dos situaciones importantes. La primera referida a que las mujeres encontraron un medio para su independencia económica y con ello abrieron los ojos a un horizonte en el que ellas podían tener un trabajo remunerado fuera de la casa; y segundo, se inició el ciclo en el que las madres se separaban del hogar para solventar una necesidad económica de la familia, y ya hubo un sentido práctico de hacerlo, tanto así que no hay una recriminación al hecho de dejar a las hijas e hijos e incluso al marido para salir a emplearse.

FLUJOS MIGRATORIOS DEL DEPARTAMENTO DE CHALATENANGO, DE LOS AÑOS 80 A LA ACTUALIDAD

La década de los años 80 del siglo pasado corresponde al momento más duro del conflicto armado salvadoreño y marca una diferencia significativa entre Comalapa y Concepción Quezaltepeque con respecto a la manera en cómo se vivió ese conflicto. Diferencia que definió sus destinos de la migración en esos años.

En Concepción Quezaltepeque, el flujo migratorio se dirigió principalmente hacia Italia, de manera particular por las personas residentes en el casco urbano de la ciudad. La circunstancia que motivó esta migración fue la situación de inseguridad que generó el conflicto armado y en consecuencia la amenaza de que sus familias y sus bienes se vieran afectados trágicamente. Estas personas que migraron, con algunas excepciones, formaban parte de familias extensas con una condición económica solvente. Eran dueños de terrenos, 
ganado, casas, etc., además, por lo menos una parte de los que se fueron, tenían alguna profesión. Este flujo migratorio a Italia presenta características muy singulares debido a que en ese momento las regulaciones migratorias les permitieron un ingreso legal, y al establecerse formaron las redes de apoyo para que otras familias quezaltecas también viajaran y se incorporan al trabajo productivo. Al migrar todo el núcleo familiar, de alguna manera rompieron la relación de responsabilidad económica con la familia extensa en la comunidad de origen. Esto debido a que esa familia ya gozaba de comodidades y de algún nivel económico que les permitiera continuar sin mayores dificultades con sus vidas. Por esa razón no existió un marcado sentimiento de compromiso u obligación moral por sacarlos económicamente adelante. Sin embargo, el lazo que no se rompió fue el del patrimonio económico, por lo cual, las remesas enviadas desde Italia contribuyeron a incrementarlo. Ninguna casa del casco urbano de la ciudad ha tenido cambios en la infraestructura y fachada. Son casas grandes, cómodas y en general bien ubicadas dentro del casco, por lo que el dinero enviado ha sido invertido en mejorar lo que ya tenían, especialmente en la ganadería. Según los datos de la alcaldía municipal —entrevista realizada en 2009 al señor alcalde municipal-, hay un aproximado de 1,200 familias quezaltecas viviendo en Italia actualmente y están ubicadas en su mayoría en la ciudad de Milán, donde tienen un fuerte lazo de cohesión que les ha llevado a organizarse como comunidad, ya que por la distancia y porque están residiendo con su familia, el retorno a Concepción Quezaltepeque por vacaciones u otro motivo no es frecuente. Por ello realizan actividades en la comunidad de destino que les permiten estar unidos y mantener los canales de comunicación con su comunidad de origen.

Comalapa, al ser afectada en menor grado por el conflicto armado, no sintió, en términos generales, la zozobra de ver amenazados sus bienes y sus vidas. Así, la principal motivación para migrar fue la búsqueda de una mejora en la calidad de vida para sus familias y dirigió su flujo migratorio hacia Estados Unidos. El flujo mayoritario salió posterior a la firma de los Acuerdos de Paz, que corresponde al cuarto periodo migratorio que señala PNUD (2005: 34) en los años comprendidos entre 1992 y 2005 . No obstante, se 
tiene conocimiento de migración hacia Estados Unidos desde finales de los años $60 \mathrm{y}$ durante los 70, pero en menor cantidad; sin embargo, fueron esas personas las que tejieron las redes para recibir a las que emprendieron el viaje en los años siguientes. En Comalapa, quienes se van son personas con recursos económicos limitados que vieron en la posibilidad de irse la única forma para salir adelante con su familia. Eso se comprueba con el flujo de remesas que hay en el pueblo. La remesa que reciben, como dice una informante «no es un gran montón» pero permite un flujo continuo de efectivo que dinamiza el comercio del pueblo; además hay un tipo de remesa monetaria que se envía exclusivamente para la mejora de la vivienda. Este hecho tiene su explicación en que las casas de muchas de las personas que se fueron no contaban, en su gran mayoría, con los servicios básicos necesarios para procurarse una vida cómoda, situación que se suma a que en muchos de los casos es el único patrimonio que poseen, pues una característica importante de las personas que se han ido para «el norte» es que no tienen tierras, ganado u otro bien. Por esa razón, las casas de quienes tienen «gente allá» son ostentosas en su construcción y es la manera más visible de mostrar a la comunidad de origen que poseen un mejor nivel de vida como resultado del trabajo, el esfuerzo y, en general, de una vida exitosa en Estados Unidos; pero también, y quizá lo más importante, es que de esta forma muestran el amor y el afecto al procurarles a sus familiares que se quedaron en un ambiente de comodidad. En la actualidad no es «posible estimar cuánta gente se ha ido», comenta el alcalde municipal de Comalapa, porque entre otros factores la gente que regresa deportada encuentra los medios para irse de nuevo, y las personas que ya residen «allá» y que tienen alguno de los estatus legales «piden» a sus familiares de aquí como residentes y se los van llevando, además de los y las que de manera ilegal se siguen yendo.

\section{TRASFORMACIÓN DE NORMAS, VALORES Y SÍMBOLOS CULTURALES ASOCIADOS A LA MIGRACIÓN}

El sentido de migrar toma diferentes matices según las circunstancias particulares de cada familia y cada persona. Difícilmente se puede generalizar al decir que los hechos y consecuencias del fenómeno migratorio que impactan en una zona del país lo hacen de igual manera en otra. Para el caso particular de Comalapa y Concepción Quezaltepeque, el 
hecho de que las personas estén saliendo desde más o menos los años 30 del siglo pasado, ha dado un sentido práctico al hecho de salir a explorar en otros horizontes una vida mejor para ellos y ellas mismas y sus familias. Este sentido práctico de asumir las migraciones en términos de que las personas lo asocian a sus experiencias de vida, ya no tanto porque ellos o ellas mismas lo experimentaran, sino porque alguien de su familia o de sus amistades en algún momento de sus vidas lo vivieron y se convirtió en parte de su ideario colectivo. La primer salida hacia Honduras, impulsada por la falta de trabajo en el propio lugar, y luego las migraciones internas hacia las cortas de café o para que las mujeres se emplearan como domésticas, también motivadas por la necesidad se suplir carencias básicas de sus familias, crearon de alguna manera las condiciones emocionales para las separaciones de la migración reciente a Estados Unidos e Italia. Esta situación permitió una separación en función de un bien común familiar, ya sea primordialmente para procurar mejoras económicas, como el caso de Comalapa, o para procurar la seguridad de la familia en el caso de Concepción Quezaltepeque.

La antesala migratoria anteriormente expuesta permite establecer un patrón de salidas en los dos pueblos donde se ha realizado este estudio. El primero motivado por la necesidad de proporcionar a las familias seguridad y bienestar económico, y el segundo determinado por los eventos políticos del país y las oportunidades generadas en otras regiones. Pero las oleadas migratorias que han sido parte de las experiencias de vida de estas dos poblaciones han marcado, sin pretenderlo, a las mujeres y hombres de diferentes generaciones, preparándoles para las separaciones siguientes. En el caso de las experiencias vividas por las mujeres, la oleada migratoria hacia Honduras dejó a las esposas, hijas o hermanas, como responsables de las familias de los hombres que tomaron la decisión de irse. Esas abuelas de hoy se fueron a «los cortes»y dejaron a sus hijas e hijos para procurarse un ingreso económico, de la misma manera que lo hicieron las que se emplearon como domésticas en San Salvador. Las madres de hoy son las que habiendo pasado esa experiencia de separación con sus abuelas y madres han migrado hacia EEUU y dejado a sus hijas e hijos. Todo este entramado determina las nuevas relaciones entre generaciones de mujeres que les 
permiten tomar la decisión de migrar solas y de dejar a sus hijas e hijos al cuidado de la familia extensa.

Este cambio de valores y significados en el cuidado y las demostraciones de afecto, en los cambios de roles dentro de la dinámicas familiares, en la comunicación, en el control del dinero y la generación del mismo y en la toma de decisiones en el hogar, son parte de los cambios que los bienes culturales que se movilizan gracias a la circularidad que las migraciones han traído a esos pueblos. Pero esos cambios también han modificado otras situaciones de la vida diaria de las personas reflejadas en sus gustos, sus nuevas formas de consumo, de divertirse y de expresar sus decisiones políticas y participar en ellas. Ese corredor cultural que se establece entre las personas que se quedan y las que se van se constata en las incorporaciones de nuevos valores.

Ese flujo migratorio ha marcado tanto en Comalapa como en Concepción Quezaltepeque el ahora de sus habitantes, modificando significativamente las expectativas de vida, valores y costumbres de manera personal. Esta situación pasa por un reacomodo en las relaciones familiares que han orillado a una recomposición que les permite seguir con sus rutinas diarias en el aquí y en el allá, sin perder el contacto emocional y económico de sus integrantes. Dichas reconfiguraciones han provocado una resignificación de lo que entendemos por familia, que la limita al modelo nuclear conyugal y a la unidad residencial, y han impuesto uno diferente en el que las personas van incorporando los nuevos bienes culturales que la comunidad de destino ofrece a las personas migrantes. Estos cambios que se incorporan en acciones, como el cuidado, la preparación de los alimentos al introducir electrodomésticos, el trato entre las personas y el uso de tecnologías para la comunicación, son parte de ese corredor cultural que se establece entre las personas que se quedan y las que se van y que impacta de manera directa a la familia y a la localidad.

Esas modificaciones que en principio tienen no solo se presentan en las dinámicas familiares, modifican también las normas y valores en las mujeres y hombres, tanto si se 
quedan como si se van, tanto en las personas mayores como en las personas jóvenes, tanto en lo colectivo como en lo individual. Por eso, al revisar el patrón migratorio de Comalapa y Concepción Quezaltepeque se puede comprender hasta dónde en estas comunidades que se encuentran dentro de un circuito trasnacional, van constantemente incorporando y modificando sus vidas cotidianas, sus costumbres, comportamientos y actitudes, a partir de la circulación de los bienes culturales que los destinos migratorios les proporcionan y que adecuan a sus propias realidades.

La opinión generalizada es que esta migración reciente de sus familiares ha sido dura, sin embargo comprenden que es la manera en que pueden salir adelante, no solo quien se queda y recibe remesas sino también quien se va y se inserta en una nueva sociedad donde busca un mejor futuro. Estas separaciones del padre, la madre, o ambos, la hermana, el hermano, el primo, etc., no es para nada desgarradora, no les supone una tragedia familiar sino todo lo contrario, la asumen como parte de un patrón incorporado desde no saben cuándo; que empezó posiblemente con el bisabuelo o el abuelo que se fue a Honduras, que continuó con la madre, el padre, el hermano o la hermana que llegaron a «los cortes», o con la madre, la tía, la hermana que se fueron a trabajar a San Salvador. Es una separación que viene dada por la practicidad que les impone la vida y que les permite continuar con sus maneras cotidianas.

Todas las experiencias de migraciones anteriores, sumadas a las experiencias de a quienes «les ha ido bien», hacen que las personas se expresen sobre el actual hecho migratorio como algo positivo para sus vidas y lo asimilen con mucha practicidad. Hay mucha claridad de que las personas que se han ido y mandan remesas están contribuyendo a que las personas que se quedan tengan un mejor nivel de vida, y si para eso ha sido necesario separarse asumen ese costo y se recomponen y reorganizan familiarmente con el propósito de seguir adelante. Esos reacomodos muchas veces pasan desapercibidos y son los cambios a nivel económico los más fácilmente observables. El casco urbano de Comalapa es una muestra de cómo la recepción de remesas ha significado cambios sustanciales en los niveles 
de vida de las personas. Van trasformándose e incorporando nuevos elementos culturales, y si tomamos en cuenta el consumo como un proceso social, un nivel de vida es un hábito, variar el nivel de vida es romper el hábito (Veblen, citado en Molina y Valenzuela 2005: 233), estableciendo con ello los parámetros de vida a alcanzar, a partir de las modificaciones de distintos aspectos culturales y simbólicos que ocurren debido al acceso a un nuevo nivel adquisitivo y modificando los hábitos, valores y relaciones sociales de las personas que reciben las remesas. Las prácticas culturales, entonces, se modifican y reconfiguran para dar paso a nuevas formas de convivencia, donde los valores y las identidades también cambian. Pero todos estos cambios están determinando que aunque las personas se vayan siguen vinculadas estrechamente a sus familias en los lugares de origen, y esa situación trae consigo vínculos de conexión que trasforman a quienes se van y a quienes se quedan. En quienes se van surgen nuevas palabras y nuevas formas de relacionarse con las personas; implicando cambios en hábitos y costumbres, formas de vestir, de comunicarse, de absorber nuevos estilos de vida, etc. Quienes se quedan trasforman procesos artesanales de la elaboración de sus alimentos, de las formas de cultivo, de las formas de satisfacer sus necesidades de aseo y aprenden a convivir con la tecnología.

Todas las incorporaciones que cada persona y cada familia realiza, ya sean tecnológicas, culturales o simbólicas, están determinando la manera en que el hecho migratorio trasforma las realidades y marca otras maneras de adaptarse a esa realidad, que para Comalapa y Concepción Quezaltepeque se trata de un sentido práctico con el que se retoma la vida cotidiana después de que el padre, la madre, o ambos, la hermana, el hermano, el hijo o la hija, toman la decisión de migrar. Este sentido práctico lleva implícito el no reclamo y la no censura a quien se va, ni por la propia familia ni por la sociedad en general. Idea que se fundamenta en el hecho de que tras de sí lleva dos oleadas migratorias en las que se aprendió a convivir con las ausencia y reconocer que migrar es una oportunidad real y concreta para resolver sus carencias. 
Por ello, en este contexto migratorio, la practicidad como resultado de estas separaciones espaciales y temporales que fragmentan a las familias permite que estas familias trasnacionales busquen las formas de mantenerse unidas y comunicadas más allá del envío y la recepción de las remesas monetarias y simbólicas. Este modelo de familia trasnacional agrega practicidad a las nuevas formas de convivencia, pues les impulsa, por un lado, a seguir sus rutinas diarias, pero por otro encuentra los medios para mantener un lazo afectivo que no se rompe ni diluye por la distancia, sino que se fortalece en dos vías: quienes se quedan saben que hay una razón importante por la que se ha fragmentado la familia, y quienes se van saben que su esfuerzo cumple el cometido que motivó el viaje. Tan práctica es la manera que asumen las migraciones que no se espera, ni en Comalapa ni en Concepción Quezaltepeque, que sean solo los hombres quienes se vayan, tampoco se espera que cuando una mujer se va no establezca una relación de pareja con otro hombre o que «estando allá» no se separe de su pareja y se «junte» con otro, esos esquemas tradicionales parecen estar cambiando como parte de las convivencias en otras culturas, donde esas conductas no son censuradas y es en la comunicación diaria que se establece entre estas familias trasnacionales que hechos como éste se tornen habituales, y las nuevas formas en que las rutinas diarias se adapte a las necesidades impuestas en el aquí y el allá se van volviendo cada vez más cotidianas.

En términos de García Canclini, está surgiendo una identidad híbrida que va asimilando otras prácticas culturales que mantiene siempre normas y valores originarios, pero que sin embargo al modificar esas prácticas tradicionales va dando paso a otro sistema de normas y valores que muestran otros significados a las relaciones de pareja, a las relaciones con las hijas e hijos y a la convivencia diaria con el entorno. Las prácticas discretas — costumbres, rituales, características de las poblaciones, etc. - que se han incorporado o modificado no son producto único de la cuestión migratoria ni de su efecto más visible, las remesas. Los cambios en las costumbre, las tradiciones y hábitos cotidianos de las personas, son el resultado de una hibridación en la que este proceso migratorio ha contribuido a través de los años a que ocurra, puesto que ha asimilado, combinado, integrado y modificado 
características culturales de los lugares de origen y los de destino, aunque siguen manteniendo sus características originales en ambos lados de la migración.

En ese sentido, un hecho particular que está produciendo un cambio importante en la estructura tradicional de Comalapa es la acción que toman las madres que viven en Estados Unidos de crear las condiciones, materiales principalmente, para que sus hijas e hijos adolescentes vivan solos como una familia separada de la familia extendida a la que quedaron encomendados. Aunque en este trabajo se hace referencia a un solo ejemplo de los dos que existen en Comalapa, ambos son ya un referente sobre cómo «se vive la vida allá» y cómo pueden, debido a las necesidades que surgen «aquí», incorporar esos cambios que le permita a la familia seguir con su vida. El ejemplo al que se hace referencia es al conflicto surgido entre la abuela y las nietas y nieto, a quienes tiene bajo su responsabilidad, ya que la nieta mayor tiene novio y la abuela no está dispuesta a lidiar con la situación.

Este hecho, que en principio puede ser tomado como un caso aislado, conlleva un significado de cambio importante por varias razones. La primera de ellas es que la madre toma la decisión de que sus dos hijas y su hijo adolescente vivan juntos fuera de la casa, porque ése es el referente que ella tiene en Estados Unidos. Luego de vivir doce años «en el norte» es lo que ve que sucede con los y a las adolescentes que cumplen la mayoría de edad, en las casas donde ella trabaja. La segunda es que tanto la abuela, la madre y la nieta no han vivido como conflicto la separación sino como un espacio donde la brecha generacional entre la abuela y la nieta no se tensiona sino que se relaja cuando se asume que las adolescentes tienen criterios para continuar con sus vidas de manera personal y bajo la responsabilidad de su propio cuido. La tercera es que estas dos adolescentes son colaboradoras activas de la vida política y social del pueblo con el consentimiento de su padre y madre desde la distancia, y alguna supervisión de la abuela. La cuarta es que esta acción muestra un nuevo patrón de conducta que las personas jóvenes están asumiendo e imponiendo al contar con la libertad que su madre y su padre en «el norte» les están dando 
como solución a un problema práctico del reacomodo y reconfiguración familiar.

Esta hibridación cultural, que se está produciendo como parte del intercambio de ideas, estilos de vida, maneras de asumir otros valores asociados con las libertades y responsabilidades individuales, está siendo parte de las trasformaciones del hecho migratorio que van más allá de los cambios que el flujo de efectivo provocado por las remesas deja ver. Tal es el caso del ejemplo arriba citado y que muestra la adopción de valores de individualidad que está sentando un precedente importante en una sociedad conservadora, donde el sentido de lo vertical ha marcado las maneras en que en las familias resuelven los problemas y además donde la última palabra la tiene la persona mayor responsable.

Estos nuevos valores de individualidad que van adquiriéndose e incorporándose a las condiciones ya existen en la comunidad de origen, se manifiestan en la autonomía de la que ahora están empezando a gozar esas adolescentes por influencias de las experiencias culturales de sus familiares en el país de destino. Esta situación es trascendental ya no solo porque en la vida familiar se han incorporado nuevas formas de conducirse y desenvolverse, que se traducen en el desapego por el resguardo de las hijas e hijos y existe ya un claro respeto por lo individual; sino que además se extiende a otras esferas de la vida social en la comunidad de origen, provocando cambios en la vida medular del pueblo, es decir, dentro del poder político. Que mujeres jóvenes se estén incorporando a las estructuras de poder denota un cambio sustancial que pasa por un nuevo reacomodo en la vida social. Las jóvenes citadas en el ejemplo anterior, a partir de la autonomía que ahora tienen, son integrantes activas de los comités locales, espacios donde la vida política y económica local se dinamiza. Estos comités — de salud, de festejos, de la iglesia, de la escuela, etc.- definen entre otras cosas los liderazgos políticos partidarios en el pueblo. Por ello el comité de festejos resulta particularmente interesante porque junta el poder político, económico y es el semillero para esos liderazgos. 
Lo anterior se concreta debido a que la «Fiesta» es hoy por hoy la máxima actividad social y comercial de Comalapa. Vale aquí hacer la salvedad de que la fiesta patronal de Comalapa, hasta el año 2000, se celebró en honor a San Francisco de Asís, santo patrono del pueblo, pero la fecha oficial de esta celebración según el calendario católico de fiestas patronales es el día 4 de septiembre. Por decisión de toda la comunidad de Comalapa, esta celebración se trasladó en el año 1964 al segundo fin de semana de enero debido a que el mes de septiembre es sumamente lluvioso, aunque esa decisión también obedeció a un factor económico, ya que en el último trimestre del año un buen porcentaje de las personas del pueblo se desplazaban a las cortas de café y su regreso se esperaba sobre finales del mes de diciembre, con lo cual, el mes de enero resultaba económicamente apropiado para las celebración.

Lo anterior provocó un hecho singular. En la actualidad se celebran, por un lado, la Fiesta patronal, y por otro la «Fiesta tradicional» o simplemente «La Fiesta». En el año 2000, a partir de las nuevas disposiciones de la Iglesia católica, que solicitaba a las comunidades celebrar el día exacto en que se conmemora al santo patrono; la fiesta patronal celebrada en enero se convirtió en «Fiesta tradicional» y se sigue celebrando con mucha solemnidad, pero no obstante su carácter oficial no incluye ninguna actividad religiosa. Este evento resulta particularmente importante en la historia reciente de Comalapa porque dividió y enfrentó a la población.

Fue a partir de ese evento que el gobierno municipal, apoyado por el comité de festejos, la «gran mayoría» del pueblo y «los que viven en el norte», decidieron dar el nombre de «Fiesta tradicional» a la celebración del mes de enero, la cual ha crecido y ha pasado de ser una fiesta de un día marcado por el calendario religioso en honor a un santo, a ser una celebración popular de una semana. Lo particular de esta fiesta es que se ha convertido en un espacio para el encuentro y el reencuentro entre las personas residentes del pueblo y las que han migrado a otros lugares del país y al «norte». Lo relevante de esta «Fiesta tradicional», más allá de ser un motor que dinamiza la economía local, radica en que es un 
espacio para que los liderazgos políticos se desarrollen y se releven, ya que es el comité de festejos, más que ningún otro, el centro del poder político y económico del pueblo. La Fiesta patronal ha pasado a un segundo plano en los ámbitos económico y simbólico, pero que congrega a la comunidad católica, constituyéndose en la actualidad en un espacio para el esparcimiento y la expresión del fervor religioso, más local; la Fiesta tradicional sin embargo es un espacio para la convivencia trasnacional y tiene un significado de pertenencia para las personas del pueblo que han migrado.

Este entramado se entreteje de manera sutil y se extiende a todos los niveles de la vida social de Comalapa y va mostrando la adopción de nuevos valores. Por esa razón es sumamente relevante que las jóvenes antes citadas se hayan incorporado al trabajo de los comités locales, porque es en ellos donde las personas tienen la oportunidad de entrar al mundo público y es el espacio para preparar a nivel de liderazgo a sus integrantes, ya que por las actividades que realizan se sitúan en un nivel de visibilidad y protagonismo frente al resto de la comunidad. Sin embargo, la pertenencia al comité de festejos, en particular, conlleva una tradición e importancia especial. Dicho comité es un ámbito donde sólo una pequeña parte de la población participa, y en términos de política partidaria es un semillero para preparar y lanzar a la palestra pública a quien en algún momento asuma la postulación para la candidatura de algún partido político. En este momento, además se está dando un cambio interesante a partir del ingreso de mujeres jóvenes al comité de festejos, lo cual reviste de una importancia reveladora, primero porque es un claro producto del hecho migratorio al incorporar otras formas de convivencia y segundo porque ha permitido que las mujeres jóvenes entren a formar parte de un espacio dominado por personas mayores y con niveles de poder y decisión importantes en el pueblo.

Esta situación otorga relevancia al hecho de que las adolescentes hayan ingresado a formar parte de dicho Comité, hasta este momento como colaboradoras y como parte del grupo que «realiza las tareas», pero están ya dentro, y como expresa el presidente del Comité: 
Ellas son las que en algún momento van a tener que asumir las responsabilidades. Lo bueno es que están aprendiendo cómo se hacen las cosas [...] Mire, ellas no lo saben ahora, pero pueden llegar a ser presidentas de Comité o hasta si quieren ser candidatas a la alcaldía porque son buenas, son bien dinámicas. Es cosa de ir aprendiendo a perder el miedo de hablar en público o a ser responsables de las actividades y esas cosas, sólo es cosa de apoyarlas...

Lo anterior es parte de las muchas modificaciones que el corredor trasnacional en el que estas poblaciones están inmersas provoca. Esos cambios en las estructuras políticas, familiares y económicas también se muestran en la revalorización y resignificación de los tiempos dedicados al ocio. Este entorno rural no tiene tradición de dedicar tiempo a la recreación, sin embargo, a partir de las vivencias de quienes se han ido, especialmente «al norte», y al insertarse en otra experiencia cultural, en la que el trabajo duro les hace apreciar y desear el tiempo de descanso para conocer, distraerse, etc., está surgiendo en estas localidades un entramado interesante en el que se junta el poder adquisitivo a partir de la recepción de remesas y las nuevas costumbres de cómo invertir tiempo y dinero en actividades de recreo. Ahora es parte de la dinámica de estas localidades destinar un tiempo para el ocio.

Pero para dedicar este tiempo hay que tener dinero y un vehículo propio, aunque no es una condición determinante. Por ello una de las primeras cosas que cambian en los hogares con residentes en Estados Unidos es que sus familiares «de allá» envían dinero para comprar un vehículo, especialmente Pick Up. Con esta adquisición adquieren otro nivel dentro de la comunidad, por un lado; y por otro es una forma de concretar los afectos y suplir las ausencias. Estas nuevas formas en que las familias se relacionan, que no se limitan a cubrir carencias económicas sino que se complementan con otras formas de expresión y comunicación entre la familia que se queda, y la que se constituye en el país de destino por quien se va, es lo que configura a la familia trasnacional. La cual toma sentido en las nuevas maneras de relacionarse y vincularse entre sí, que trascienden a la corresidencia y la presencia física, provocando otras maneras de entender los afectos, los cuidos, la 
comunicación y las relaciones entre madres, padres, hijas, hijos, hermanas, hermanos, tías, tíos, etcétera.

Estas nuevas relaciones que se articulan en torno a las familias trasnacionales se concretan en el envío de remesas económicas y sociales, donde las primeras constituyen el envío de dinero por parte de quien se va hacia la familia que se queda, porque «simbólicamente el envío de remesas representa el mantenimiento del compromiso del migrante con su familia; mientras siga llegando dinero, se puede suponer que de una u otra forma el afecto se conserva» (Moncayo, citado en Zapata 2009: 1754). Las remesas sociales en cambio son el conjunto de valores, estilos de vida, pautas de comportamiento y capital social que se da entre las comunidades de origen y de destino (Levitt 2001), son todos aquellos intercambios entre las familias que les permite mantenerse en comunicación - fotografías, regalos, visitas ocasionales, llamadas telefónicas, correos electrónicos, etc.- y mantener los lazos de afecto. Las remesas, tanto las económicas como las sociales, les permiten a las familias trasnacionales mantener y visibilizar los lazos entre el país de destino y el de origen. Les permiten a las personas inmigrantes mantener vivas sus relaciones más allá de las fronteras. Todo este flujo de remesas sociales y económicas son las que están trasformando diferentes dimensiones de la vida rural.

\section{CONCLUSIONES}

Las diferentes particularidades de estos dos pueblos dejan ver que sus vidas cotidianas están en constante cambio, y que además esos cambios están marcando otras posibilidades de ver el mundo y expandir los horizontes desde lo local, mostrando que la vida habitual de las personas se adapta, se recompone y se organiza en función de seguir adelante a pesar de las ausencias de madres, padres, hermanas, hermanos, etc. Esa manera de retomar la cotidianidad en el aquí y en el allá no recrimina el hecho de «irse», sino que lo valora y le da un significado práctico a las separaciones. Esta situación da sentido a lo trasnacional y abre paso a las hibridaciones culturales que cambian valores e identidades al incorporar otros elementos culturales. 
Los cambios observados y documentados en esta investigación muestran que el patrón migratorio actual, por lo menos para las dos poblaciones donde se realizó este estudio, claramente indican que hombres y mujeres viajan por igual, que las mujeres no están viajando solamente por reunificación familiar y que no hay una tendencia a señalar el hecho migratorio como responsable de la desintegración familiar o de otros fenómenos asociados a la violencia social de El Salvador. El fenómeno migratorio además se asocia como algo positivo, como una oportunidad en tanto que las remesas monetarias y sociales están incorporando cambios en la vida de las personas que se quedan.

Por otra parte, es preciso no perder de vista el hecho de que las personas en Comalapa y Concepción Quezaltepeque tengan casi un siglo migrando - primero a Honduras desde más o menos los años 30 y luego en las migraciones internas, especialmente al occidente del país por las cortas estacionarias de café-, puesto que esa situación permite comprender el sentido de practicidad con el que se toman las ausencias de sus familiares. Las separaciones por el fenómeno migratorio no paralizan la vida cotidiana, por el contrario, las familias se recomponen y reorganizan para seguir con su día a día, «aquí» y «allá». Los roles de sus integrantes cambian y se reacomodan para asumir las decisiones, el soporte emocional, la distribución de la remesa que llega, etcétera.

Es relevante, además, que en la recomposición familiar, por necesidad práctica que se está dando en las familias que se quedan «aquí», ha surgido una manera de diferenciarse de la familia que está «allá». Así, quienes se quedan en la comunidad de origen se llaman la «otra» familia con respecto a la nueva que han formado sus madres y padres en el lugar de destino, indistintamente si su madre y padre viven juntos allá y tienen ahora otras hijas e hijos, o si la madre y el padre viven con una nueva o nuevo compañero y han tenido hijas e hijos con esta nueva pareja. Es parte del vocabulario de la familia que se queda aquí comentar sobre que «aunque tengan su familia allá, nunca dejan de mandarnos lo que necesitamos». Este argumento refuerza el concepto de familia trasnacional, porque 
evidencia el lazo emocional y económico que no se rompe, sino que se mantiene a través de la comunicación telefónica, las visitas esporádicas y el envío de remesas.

Pero este circuito trasnacional en el que están inmersas estas dos poblaciones, además de reacomodar de manera práctica las familias, ha traído consigo cambios que están modificando el paisaje cultural. Estos cambios que pasan de lo individual a lo colectivo y de lo familiar a lo local, están modificando los valores y concepciones de las personas en el ahora, en el «aquí» y en el «allá», y dan paso a nuevas formas de convivencia. Todas las incorporaciones que cada persona y cada familia realizan, ya sean tecnológicas, culturales o simbólicas determinan la manera en que el hecho migratorio trasforma las realidades y marca otras maneras de adaptarse a esa realidad, que para este estudio se traduce en un sentido práctico con el que se retoma la cotidianidad familiar en la comunidad de origen.

Por lo anterior, una veta de investigación futura es el desarrollo local de las comunidades de origen a partir del destino de la migración.

\section{FUENTES DE CONSULTA}

Asociación de Capacitación e Investigación para la Salud Mental, 2008, Investigación diagnóstica de esfuerzos microregionales del Departamento de Chalatenango, Acisam, El Salvador.

Alcaldía Municipal de Comalapa, 2004, Plan estratégico participativo 2004-2008, El Salvador.

De Burgos, Hugo, 2001, Chalatenango, Historia Urbana, Concultura, El Salvador.

Dirección General de Estadística y Censos, 2008, VI censo de población y V de vivienda 2007, Ministerio de Economía, DIGESTYC El Salvador. 
Fundación Nacional para el Desarrollo, 2007, Migración y desarrollo local: Una aproximación desde los municipios de Pasaquina, Santa Elena y Acajutla, FUNDECARECEN, El Salvador.

Gammage, Sara, 2004, Viajeros y Viajeras en El Salvador: Enlazando Mundos, Estrechando Vínculos, Destination D.C., Working Paper, n. 2.

García Canclini, Néstor, 2003, Culturas hibridas. Estrategias para entrar y salir de la modernidad, Grijalbo, México.

Lara M., Carlos Benjamín, 2003, Joya de Cerén. La Dinámica Sociocultural de una Comunidad Semi-Campesina de El Salvador, Concultura, El Salvador.

Lara M., Carlos Benjamín, 1994, salvadoreños en Calgary: El proceso de configuración de un nuevo grupo étnico, Concultura, El Salvador.

Molina, José Luis y Hugo Valenzuela, 2006, Invitación a la antropología económica, en revista-redes en rediris.es/recerca/jlm/docencia.../manual_ae.pdf [consulta: 1 de octubre de 2012].

Marroquín, Amparo, 2006, El sueño centroamericano: Un acercamiento a la migración y cultura salvadoreña, UCA, El Salvador.

Programa de las Naciones Unidas para el Desarrollo, 2005, Informe para el desarrollo humano en El Salvador 2005. Una nueva mirada al nuevo nosotros: el impacto de las migraciones, PNUD, El Salvador.

Programa de las Naciones Unidas para el Desarrollo, 2007, Informe para el desarrollo humano en El Salvador 2007. El empleo en uno de los pueblos más trabajadores del 
mundo, PNUD, El Salvador.

Programa Salvadoreño de Investigación sobre Desarrollo y Medio Ambiente, 2006 Avanzando hacia el ecoturismo comunitario en la Mancomunidad La Montañona, Chalatenango, PRISMA, El Salvador.

Santillán, Diana y María Eugenia Ulf, 2006, Destinatarios y usos de remesas. ¿Una oportunidad para las mujeres salvadoreña?, Unidad Mujer y Desarrollo Proyecto «Políticas laborales con enfoque de género», CEPAL, Chile.

Zapata, Adriana, 2009, «Familia transnacional y remesas: padres y madres migrantes», Rev.latinoam.cienc.soc.niñezjuv, $\quad$ v. $\quad 7, \quad$ n. $\quad 2$, pp. 1749-1769, en http://www.umanizales.edu.co/revistacinde/index.html [consulta: 1 de octubre de 2012].

\section{NOTAS}

\footnotetext{
${ }^{1}$ Quiero expresar mi especial agradecimiento al Dr. Luis Rodríguez Castillo, investigador del PROIMMSEIIA-UNAM, por animarme a escribir este artículo y por dedicarme su valioso tiempo para enriquecer mis ideas con sus comentarios y observaciones.
}

Fecha de recepción: 17 de noviembre de 2012.

Fecha de aceptación: 25 de febrero de 2013. 